\title{
A mediação pedagógica e o programa de escrita inventada na alfabetização de jovens e adultos
}

\author{
Francisca Izabel Pereira Maciel" \\ Juliane Gomes de Oliveira*
}

\section{Resumo}

A presente investigação insere-se no quadro teórico dos estudos sociointeracionistas e da pesquisa colaborativa e tem como objetivo analisar as estratégias de mediação pedagógica nas produções escritas de grupos de alunos jovens e adultos em processo de alfabetização. Foram realizadas análise e categorização das mediações ocorridas ao longo do programa de intervenção na escrita inventada (PEI) em diálogo com pesquisas desenvolvidas em Portugal e no Brasil. A pesquisa com escrita inventada é definida como uma ação que gera transformações no pensamento do alfabetizando, visto que mobiliza a sua atenção para as pautas sonoras das palavras e para a forma como pode registrá-las e pode favorecer o processo de reflexão metalinguística implicado na aprendizagem inicial da língua escrita. O conjunto dessas interações com os sujeitos adultos demonstrou que o exercício da escrita colaborativa pode desenvolver o processo de reflexões coletivas e individuais para o desenvolvimento na apreensão da língua escrita.

Palavras-chave: Mediação pedagógica; Programa de escrita inventada; Alfabetização; Educação de jovens e adultos.
Graduação em Pedagogia pela Universidade Federal de Minas Gerais, Belo Horizonte/MG/Brasil/UFMG. Mestrado e Doutorado em Educação/UFMG. Pós doutorado/ PUC/SP (2005-2006), UFPB (2010-2011) e na Universidade do Minho (2016-2017) . Professora Titular da Faculdade de Educação/UFMG. Integra o corpo docente da Pós-Graduação da Faculdade de Educação da UFMG. Coordena o grupo de pesquisa: ?Alfabetização no Brasil: o estado do conhecimento?, registrado no Diretório dos Grupos de Pesquisa do CNPq. Membro do Comitê Gestor do Centro de Estudos Africanos da UFMG (2018-2022). Diretora do Centro de Alfabetização, Leitura e Escrita (Ceale), da Faculdade de Educação da UFMG (20072010 e 2018-2020). Coordenou o GT de Alfabetização/ Anped (2001-2003). Coordenadora Adjunta do PNAIC na UFMG (2015-2016). Coordenadora do Projeto de Extensão de Alfabetização de jovens e adultos (PROEF1) da UFMG. Participou de missões de cooperação técnica do Brasil com países africanos - Cabo Verde (2005-2006) e São Tomé e Príncipe (2006-2012), na formação de alfabetizadores de jovens e adultos. Coordenou o Projeto de Mobilidade CAPES/AULP em Sao Tomé e Principe (Africa) - 2012-2017.Principais áreas de atuação: alfabetização e letramento; alfabetização, leitura e escrita de crianças, jovens e adultos; história da leitura, da escrita e dos métodos de alfabetização. E-mail: emaildafrancisca@ gmail.com

** Doutora e mestre em Educação pela linha de pesquisa em Educação e Linguagem da Faculdade de Educação da Universidade Federal de Minas Gerais. Graduação em Pedagogia pela mesma instituição. Atuou como docente de curso superior, ministrando as disciplinas: Educação de Jovens e Adultos; Grandes Pensadores da Educação; Pedagogia em espaços não-escolares; Tópicos em educação: currículo e Estágio Supervisionado na EJA. É pesquisadora do CEALE- FaE/UFMG, integra o Grupo de Pesquisa em Alfabetização (GPA) e atua também na formação continuada de professores do ensino fundamental. Alfabetizadora da Educação de Jovens e Adultos na RME/BH e possui experiência na área de políticas públicas para a EJA e coordenação pedagógica no $1^{\underline{0}}$ e $2^{\underline{0}}$ ciclos. E-mail: jugomes16@hotmail.com

Data de submissão: dez. 2020 - Data de aceite: mar. 2021

http://dx.doi.org/10.5335/rdes.v17i01.11393 


\section{Introdução}

Neste artigo, propomos refletir sobre as categorias de análise das mediações ocorridas no desenvolvimento de uma pesquisa com o Programa de Escrita Inventada (PEI) no coletivo de adultos em processo de alfabetização. Durante as atividades de escrita inventada que envolveram três grupos de alfabetizandos da educação de jovens e adultos da Rede Municipal de Ensino de Belo Horizonte (RME-BH), buscamos analisar e identificar ações do mediador que favoreceram o processo de reflexão e de escrita de palavras pelos sujeitos participantes, bem como caracterizar e categorizar essas ações na dinâmica de interação entre mediadora e alunos.

Inicialmente, apresentaremos os princípios e a concepção teórico-metodológica orientadores dos Programas de Escrita Inventada, com destaque para as pesquisas portuguesas (ALVES MARTINS; SALVADOR; FERNÁNDEZ, 2017; ALBUQUERQUE; ALVES MARTINS, 2018, 2019) e brasileiras (MONTEIRO; SOARES, 2014; SOARES, 2016; RESENDE; MONTUANI, 2019). Na sequência, apresentamos as categorias de intervenção/mediação que subsidiaram a pesquisa com os grupos de alunos. Na terceira parte, apresentamos as análises qualitativas de excertos de escrita dos alfabetizandos de acordo com as categorias de mediação. A análise permite compreender a importância de aspectos da mediação pertinentes para a compreensão da prática desenvolvida com o público da EJA.

O termo escrita inventada denomina o resultado das produções dos alunos, sejam eles crianças ou adultos, com registros de letras conhecidas por eles, que nomeamos como registros inventados. Nossa pesquisa ancora-se no conceito de escrita inventada utilizado por Soares (2016), inicialmente introduzido por $\operatorname{Read}(1971,1975)$ e por Chomsky (1971), e diz respeito às escritas "precoces" das crianças, feitas antes mesmo do domínio das convenções do sistema de escrita e do ingresso no ensino formal. Essas produções gráficas iniciais fornecem informação relevante sobre a forma como a relação entre oralidade e escrita é percebida pelos sujeitos, que, por sua vez, repercute na adequação das correspondências grafema-fonema nas suas produções escritas (ALBUQUERQUE; ALVES MARTINS, 2018).

Os Programas de Escrita Inventada (PEI) em Portugal e no Brasil se baseiam no método de pesquisa colaborativa e, em sua maioria, tratam de investigações direcionadas às escritas inventadas pelos participantes em sua atuação coletiva, instigada pelo mediador no processo de aquisição da escrita. Caracterizam-se como encontros/sessões previamente planejados, realizados por um mediador ou docente com pequenos grupos de es- 
tudantes em processo de alfabetização (ALBUQUERQUE; ALVES MARTINS, 2019; OLIVEIRA; MACIEL, 2019).

As relações de troca entre os componentes do grupo e entre o grupo e o mediador são eixos norteadores das sessões para a escrita das palavras. Essa concepção vai ao encontro das teorias de aprendizagem de Vygotsky (1989), que tratam as relações de troca entre os pares como impulsionadoras das aprendizagens. As interações, em geral, provocam dúvidas, conflitos cognitivos e podem desencadear processos de desenvolvimento interno, transformando reelaborações em novos significados e, consequentemente, em novos conhecimentos individuais. $\mathrm{O}$ teórico apresenta a linguagem como instrumento mediador do intercâmbio dos planos particular para o intrapessoal, constrói a possibilidade de apropriação, de tornar singular e particular em cada sujeito o que foi apreendido no plano interpessoal. Esse pensamento, que se construiu na relação dialógica entre os sujeitos, guarda em si o modo singular de ser e de estar no mundo que, mediado pela fala, revela vivências carregadas de sentidos, dos quais o sujeito se apropria (VYGOTSKY, 1979). Desta forma, os sistemas de interação produzidos pela mediação não só interferiram no contexto de socialização e exposição das hipóteses como também no processo de construção da aprendizagem e reflexão sobre a língua escrita no Programa de Escrita Inventada.

\section{A pesquisa com os adultos}

Sabemos que nos últimos anos os estudos na alfabetização e letramento de jovens e adultos trouxeram avanços teóricos e práticos na compreensão da construção da escrita por este público. A partir de meados da década de 1980, anunciaram-se, sob a influência da abordagem cognitivista, concepções baseadas nas contribuições da Psicogênese da Língua Escrita, formuladas por Ferreiro e Teberosky (1985), com base nos princípios piagetianos, e nas contribuições advindas da nova concepção de linguagem interacionista formuladas pelas ideias de Vygotsky (1979). Segundo Kleiman e Vóvio (2013), são as atualizações com as questões teórico-metodológicas que possibilitam mudanças nos olhares e nas formas de conceber e desenvolver a alfabetização na prática escolar com adultos.

Contudo, mesmo com os avanços, os esforços empreendidos ainda são poucos diante do tamanho do desafio de se compreender a construção do sistema de escrita alfabético (SEA) e as interfaces que envolvem o domínio competente da língua (SOARES, 2016). Nesse contexto, não é por acaso que se tornam relevantes as pesquisas realizadas sobre a aquisição da língua escrita pelo adulto. Os estudos recentes investem na busca 
de maior identidade pedagógica e política; e na preocupação epistemológica e metodológica da procura de um lugar, legitimamente próprio, para o campo da Alfabetização de Jovens e Adultos. Isso provocou esforços dos mais diversos grupos, tanto dos movimentos sociais, como dos pesquisadores, em favor de aprofundar os saberes relativos ao campo da Educação de Jovens e Adultos (EJA) e da necessidade de formações e pesquisas específicas para lidar com questões que envolvem o ensino da língua materna e o desenvolvimento das habilidades linguísticas, leitura e letramento (FREITAS; RIBEIRO; MOURA, 2020).

É neste campo de princípios e demandas da alfabetização na EJA que esta pesquisa se apresenta. Buscamos compreender os processos metalinguísticos vividos pelos alfabetizandos da EJA em contato com a escrita de palavras em situação de mediação e interação/troca de saberes. Sendo assim, esse estudo de escrita inventada optou-se pela escolha de três grupos de alfabetizandos da educação de jovens e adultos da Rede Municipal de Educação de Belo Horizonte (RME-BH), ${ }^{1}$ dois deles com três alunos e um com uma dupla de alunos, totalizando oito alfabetizandos. Os alfabetizandos foram selecionados por meio de uma atividade diagnóstica em três turmas de alfabetização, com escolha daqueles que apresentavam um perfil de escrita em fase inicial de construção do sistema alfabético. Os grupos possuíam características heterogêneas em relação à faixa etária, assim como experiências diferenciadas com a cultura escolar, embora todos se encontrassem em fase inicial da alfabetização. Foram realizadas oito sessões presenciais com cada grupo, com a escrita de três palavras em cada sessão. ${ }^{2}$ Os encontros foram realizados duas vezes por semana, durante cinco semanas. Cada sessão tinha a duração de 20 a 30 minutos, e os alfabetizandos eram instados a discutir entre si, a expor, a argumentar e a chegar a um acordo sobre as letras que deveriam ser usadas para escrever a palavra ditada pela mediadora. ${ }^{3}$

A dinâmica da escrita se deu a partir das interações entre os integrantes dos grupos e a mediadora. Eles foram levados a pensar sobre a forma da escrita das palavras, levantando hipóteses sobre a constituição das letras para gerar a escrita, refletindo sobre as relações entre oral-escrito, as correspondências grafo-fonéticas e as regras implícitas associadas ao sistema de escrita, assimilando novos conhecimentos e competências do sistema alfabético de escrita (ALBUQUERQUE; ALVES MARTINS, 2019).

O papel da mediadora foi instigar a reflexão e aguçar a dinâmica da escrita colaborativa, analisando as formas de escrever as palavras ditadas oralmente, discutindo as suas ideias para chegar a 
um consenso sobre as letras mais adequadas para representar cada palavra. A mediadora teve um papel crucial na interação e na ação dos integrantes, pois estimulava a participação, o consenso entre os alunos e a explicitação de suas hipóteses sobre a língua nas discussões, questionando-os de forma a verbalizar seus pensamentos e reflexões. Esta função mediadora, baseada na perspectiva vygotskiana (1989), que atribui um papel determinante à influência da interação social e cultural sobre o desenvolvimento do sujeito, permitiu analisar os comportamentos e incentivar os participantes a refletir sobre a escrita, potenciando uma dinâmica de interação em torno da escrita colaborativa.

A base metodológica usada pela mediadora como fundamento de suas intervenções estabelece que estas devem ter efetividade na interação social durante o processo de desenvolvimento do alfabetizando em situação de escrita coletiva, uma vez que a dimensão social e a individual se unem pela interação por meio da argumentação (VYGOTSKY, 1989).

\section{As categorias de mediação}

No Programa de Escrita Inventada, as categorias de mediação auxiliam o mediador/professor a guiar e auxiliar as reflexões dos estudantes. É importante que o mediador ou professor conheça as características do seu grupo, para entender o processo de desenvolvimento de cada sujeito e, assim, atuar de forma mais interativa na experiência coletiva dos alfabetizandos na escrita das palavras propostas. Dessa forma, o mediador desempenha um papel fundamental no desenvolvimento dos Programas de Escrita Inventada e necessita de preparo para conseguir conduzir com sucesso suas intervenções (ALVES MARTINS; SILVA, 2009).

Nas sessões do Programa de Escrita Inventada com o EJA, seguimos as etapas de pesquisas anteriores de Lanza (2018), Resende e Montuani (2020). As autoras desenvolveram categorias de mediação entre o mediador e as crianças, adequando-as ao seu grupo pesquisado. Nós também adaptamos as categorias às características próximas ao que foi vivenciado nas sessões com os estudantes adultos. A partir desses referenciais, foi possível para esta pesquisa ressignificar e também criar outras categorias adequadas ao público pesquisado, considerando as especificidades do programa com os adultos e a própria experiência vivenciada nas intervenções pela mediadora. ${ }^{4}$

Assim como nas pesquisas citadas do PEI, todas as sessões foram transcritas na sua integralidade e organizadas em arquivos em formato de grades ou células para permitir maior facilidade no momento de seleção e agrupamento. Realizamos uma análise geral de cada grupo 
com o estudo dos vídeos, das anotações em diário de campo e da leitura das transcrições. Após um estudo detalhado sobre o perfil de cada grupo, evidenciamos suas similaridades e diferenças e realizamos a análise de outras grades de categorização, construindo nosso próprio agrupamento de intervenções. É uma tarefa que demanda tempo, com vários retornos às gravações, comparando-as às transcrições, acrescentando os gestos corporais e expressões de sentimentos dos participantes e da mediadora, buscando aprofundar e refinar a análise das sessões, observando as intenções e ações da mediadora, suas decorrências, o contexto em que elas apareciam e os impactos no comportamento dos participantes. As expressões corporais, tais como esfregar as mãos, colocar a mão na cabeça, deixar as mãos postas, gestos que vinham acompanhados de expressões de alívio, dificuldade, incapacidade, satisfação, entre outros, foram muito comuns durante as sessões. Analisar detalhadamente as gravações e as anotações após cada sessão foi fundamental para definir, refinar e inserir novas categorias.
Adaptamos e reelaboramos as categorias em um exercício de analisá-las sessão por sessão até se consolidarem e se tornarem mais adequadas aos eventos vivenciados e à representação do perfil dos grupos. Nesse caminho, o Quadro 1 apresenta uma síntese da organização das categorias de mediação com o EJA.

Ao final dessa etapa da pesquisa, identificamos sete categorias e quatro subcategorias de intervenção com alfabetizandos jovens e adultos. Elas foram caracterizadas a partir de ações específicas e recorrentes da mediadora junto às respostas, perguntas, hipóteses dos sujeitos. As categorias são: gestão; questão; pista; retomada; feedback; registro e sintese. E as subcategorias são: inferência/indagação; confronto; incentivo e avaliação. 
Quadro 1 - Grade de categorias de mediação

\begin{tabular}{|c|c|c|c|}
\hline CATEGORIAS & DEFINIÇÃO & SUBCATEGORIA & FUNÇÃO \\
\hline GESTÃO & $\begin{array}{l}\text { Solicitação de participação } \\
\text { dos sujeitos (expressão de } \\
\text { opiniões, tomada de } \\
\text { decisões coletivas). } \\
\text { Direcionamento para } \\
\text { realizar uma tarefa (quem } \\
\text { vai ler?; quem vai } \\
\text { escrever?; quem vai } \\
\text { falar?). }\end{array}$ & & $\begin{array}{l}\text { Garantir a participação de } \\
\text { todos na tarefa. }\end{array}$ \\
\hline \multirow[t]{2}{*}{ QUESTÃO } & $\begin{array}{l}\text { Introdução de um } \\
\text { problema ou de uma ideia } \\
\text { para que os participantes } \\
\text { discutam a relação } \\
\text { letra/som. }\end{array}$ & $\begin{array}{l}2.1 \\
\text { Inferência/indagação }\end{array}$ & $\begin{array}{l}\text { Conduzir a percepção: } \\
\text { (i) do som e de sua relação } \\
\text { com o escrito; } \\
\text { (ii) da sequência das letras } \\
\text { na palavra; } \\
\text { (iii) da quantidade de letras } \\
\text { na palavra. }\end{array}$ \\
\hline & & 2.2 Confronto & $\begin{array}{l}\text { Confrontar as hipóteses } \\
\text { elaboradas pelos participantes } \\
\text { com a escrita correta das } \\
\text { palavras. }\end{array}$ \\
\hline PISTA & $\begin{array}{l}\text { Fornecimento de pistas } \\
\text { como estratégias para a } \\
\text { análise fonológica } \\
\text { (prolongamento de } \\
\text { fonema, separação de } \\
\text { sílabas etc.). }\end{array}$ & & $\begin{array}{l}\text { Facilitar a análise fonológica. } \\
\text { Facilitar a análise entre partes } \\
\text { orais da palavra e partes } \\
\text { escritas. }\end{array}$ \\
\hline RETOMADA & $\begin{array}{l}\text { Recapitulação de ideias } \\
\text { importantes dos } \\
\text { participantes para fazer o } \\
\text { pensamento do grupo } \\
\text { avançar. }\end{array}$ & & $\begin{array}{l}\text { Evidenciar ideias pertinentes } \\
\text { na discussão do grupo, além } \\
\text { de trazer hipóteses já } \\
\text { verbalizadas/anunciadas pelo } \\
\text { participante para dar } \\
\text { continuidade ao seu } \\
\text { raciocínio. }\end{array}$ \\
\hline \multirow{2}{*}{ FEEDBACK } & $\begin{array}{l}\text { Atuação da mediadora } \\
\text { para incentivar o } \\
\text { posicionamento e ações } \\
\text { (escrita) dos participantes. }\end{array}$ & 5.1 Incentivo & $\begin{array}{l}\text { Estimular o posicionamento } \\
\text { dos participantes na defesa de } \\
\text { suas hipóteses. }\end{array}$ \\
\hline & $\begin{array}{l}\text { Confirmar ou contrapor as } \\
\text { ideias elaboradas e de } \\
\text { conhecimentos } \\
\text { demonstrados pelos } \\
\text { participantes. }\end{array}$ & 5.2 Avaliação & $\begin{array}{l}\text { Confirmar ou contrapor a ideia } \\
\text { do participante. }\end{array}$ \\
\hline REGISTRO & $\begin{array}{l}\text { Escrita colaborativa da } \\
\text { palavra ou parte da palavra } \\
\text { feita por um participante. }\end{array}$ & & $\begin{array}{l}\text { Monitorar o andamento da } \\
\text { escrita por meio do registro. }\end{array}$ \\
\hline SÍNTESE & $\begin{array}{l}\text { Explicação da mediadora } \\
\text { com intenção didático- } \\
\text { pedagógica sobre as } \\
\text { propriedades e o } \\
\text { funcionamento do sistema } \\
\text { de escrita alfabético após o } \\
\text { confronto com a escrita } \\
\text { convencional. }\end{array}$ & & $\begin{array}{l}\text { Fornecer explicação sobre a } \\
\text { produção da escrita coletiva } \\
\text { no final das sessões. }\end{array}$ \\
\hline
\end{tabular}

Fonte: Elaborado pelas autoras. Adaptado do Grupo de Pesquisa em Alfabetização (GPA), CEALE/FaE/UFMG, 2018 
A seguir, iremos descrever cada uma das categorias e subcategorias apresentadas pelo Quadro 1. A primeira delas é a gestão, que tem a função de gerir e organizar a participação de todos os alunos no grupo. Essa categoria também buscou promover a maior interação entre os alfabetizandos, a fim de facilitar a escrita colaborativa das palavras, fomentando um clima favorável à argumentação entre os participantes. Os estudantes do EJA, de um modo geral, são introspectivos e, em nossa pesquisa, como era esperado, foram incialmente menos participativos. Agestão buscou ativar as falas individuais e a escuta para o outro, assim como as trocas de ideias e discussão em torno delas. Vimos que foi preciso gerir a colocação de opiniões, com argumentação e defesa, e a tomada de decisões coletivas, com o objetivo de garantir uma escrita coletiva consensuada. Alguns exemplos podem ser citados: pedir a um aluno para ditar letras que serão escritas por outro colega; verificar se os estudantes manifestaram acordo ou desacordo sobre a hipótese do colega; pedir para ouvirem o que o outro tem a dizer para, assim, emitir e/ou defender sua própria opinião.

A categoria questão inclui duas subcategorias: inferência/indagação e confronto. A categoria questão tem um protagonismo dentro do Programa de Escrita Inventada: promove as reflexões em torno da escrita das palavras por meio de perguntas e introduz um problema/ questão com objetivo de provocar/gerar avanços nas concepções dos estudantes.

Dentro dessa categoria, identificamos mediações que buscaram uma reflexão específica sobre as relações entre letra-som, sequência de registro e quantidade de letras na escrita dos estudantes. Para esses casos, utilizamos a subcategoria nomeada inferência/indagação. A inferência ou indagação objetivava levar os participantes à verbalização de suas hipóteses e o avanço do pensamento do grupo. A subcategoria confronto ocorre quando a mediadora apresenta a escrita convencional, anunciada como uma escrita produzida por outro grupo de estudantes da alfabetização do EJA. O confronto é o momento em que os participantes podem comparar e/ou confirmar suas hipóteses e colocar em questionamento as duas produções.

A categoria questão e suas subcategorias favorecem reflexões metalinguísticas durante produção dos estudantes, em períodos distintos vividos na intervenção: seja no início da escrita, conduzindo-os a refletir sobre as relações que há ou não entre o som e o escrito, a sequência das letras na palavra, a quantidade de letras na palavra; seja depois, explicitando suas opiniões, percebendo e descobrindo novas letras no decorrer da sessão, ou no próprio comparativo entre a escrita produzida e a escrita convencional.

Definimos a categoria pista como a atitude da mediadora em promover si- 
nais ao grupo para a percepção dos sons. $\mathrm{Na}$ pista, é comum o mediador realizar o prolongamento de som para evidenciar uma marcação fonêmica. No grupo pesquisado, constatamos a recorrência dos adultos em alongar ou evidenciar um fonema com entonação mais acentuada, era um recurso natural para perceber quais letras usariam para escrever a palavra.

A retomada tem como característica a recapitulação de ideias verbalizadas/ oralizadas pelos sujeitos no decorrer dos diálogos, mas que não foram efetivadas na escrita. A retomada foi uma ação da mediadora para "reavivar" o foco na palavra trabalhada, como um exercício para chamar a atenção dos alfabetizandos à demanda de reelaboração sobre suas próprias hipóteses. A mediadora pedia para dizerem com qual palavra estavam trabalhando ou verbalizava oralmente a palavra em questão para refletirem sobre 0 acréscimo de determinada letra.

A categoria feedback tem por definição promover um retorno das impressões da mediadora sobre as hipóteses e questionamentos apresentados pelos alunos. Como subcategoria do feedback, temos incentivo: ela abarca a atuação da mediadora para incentivar o posicionamento e ações dos participantes em expor suas opiniões ao restante do grupo. Percebemos, pelo comportamento dos sujeitos de nossa pesquisa, que a mediadora necessitou tomar atitudes positivas, com falas, gestos e ações de estímulo, visando maior participação e protagonismo dos alfabetizandos. Sabemos que os alfabetizandos do EJA já trazem o estigma de fracassos na aprendizagem da leitura e da escrita e o preconceito de serem analfabetos. $\mathrm{O}$ medo de errar é uma constante. Para amenizar a insegurança, a mediadora agia com falas de motivação, tentando apoiar a exposição de suas ideias e realizar o registro do que haviam pensado "sem o medo de errar". O incentivo foi uma subcategoria muito importante para eles na participação e na continuidade das atividades propostas.

A avaliação, subcategoria do feedback, era demandada pelos participantes principalmente por meio do reforço/da aprovação ou do desacordo da mediadora com os conhecimentos e ideias elaboradas. Em vários momentos, a mediadora precisou expor sua opinião em tom de afirmação; em outros, de estranhamento, buscando o avanço na escrita e no andamento das discussões nos grupos.

A categoria registro corresponde à escrita do grupo e apresenta o passo a passo do registro dos alunos na constituição da escrita das palavras. Sua função é apresentar o caminho dos estudantes com o registro das letras realizado por eles próprios. $\mathrm{O}$ registro tem uma função de concretizar as decisões consensuadas do grupo, além de ser fonte de apoio para resgatar o caminho percorrido na constituição da escrita. 
A última categoria, sintese, tem, em nossa pesquisa, o sentido de anunciar uma explicação final da mediadora sobre a constituição da palavra trabalhada. Asíntese possui uma intenção didático-pedagógica, pois esclarece dúvidas percebidas pela mediadora no decorrer das discussões, sendo, contudo, elucidadas somente ao final das sessões, após o momento de confronto com a escrita convencional.

Na relação adulto/mediador/professor, principalmente para aqueles que estão no processo de alfabetização, a síntese tem o sentido de um retorno respeitoso, que indica que os adultos não estão sendo usados como "cobaias", como alguém que não sabe nada. Nesse sentido, a ação de explicar com detalhamento e realizar uma síntese tem a intenção de dar um pouco de respostas às tantas perguntas feitas por nós, mediadores, e também às perguntas surgidas por eles durante as sessões.

Ao finalizar nossa exposição sobre a grade de categorizações, gostaríamos de esclarecer que, assim como em outros estudos de mediação com a escrita inventada, como o de Resende e Montuani (2020, p. 13), neste estudo, a criação de categorias não pode ser vista como "uma camisa de força", pois as formas de categorizar e os tipos de mediação podem variar dependendo das situações de interação, do perfil do grupo, dos objetivos da pesquisa/mediação, da etapa de aprendizagem, das idades e do temperamento dos sujeitos pesquisados.

\section{Análise qualitativa das mediações com os grupos do EJA}

Gostaríamos de apresentar, nesse momento, um tópico que reflete sobre as mediações ocorridas com o público da alfabetização do EJA, apresentando, por meio de trechos de episódios, as categorias destacadas no processo de interação com os sujeitos pesquisados. Elas reafirmam o papel das mediações sociais no processo de desenvolvimento da aprendizagem da escrita pelos alfabetizandos do EJA, demonstrando que as argumentações da mediadora e dos estudantes foram facilitadoras nas reflexões e construções de hipóteses sobre a escrita de palavras (VYGOTSKY, 1979).

De antemão, esclarecemos que as ações e interações dos sujeitos pesquisados envolveram interpretações contínuas e particulares em cada episódio e as análises evidenciaram situações subjetivas em relação às classificações das categorias, demonstrando interfaces e conexões de estreitamento entre elas. Por isso, reforçamos que nossas análises das mediações podem variar dependendo das situações de interação, das vivências de cada momento, do temperamento e das relação entre os participantes.

A seguir, transcrevemos três trechos de sessões do programa de escrita inventada para a análise com base na demons- 
tração do sistema de categorização. $\mathrm{O}$ primeiro excerto é um trecho do episódio da escrita da palavra TEIA. O segundo trecho corresponde à escrita da palavra MEDO, e o terceiro excerto ilustra a finalização da mediação da escrita de VIU. ${ }^{5}$ Os exemplos elucidam as interações verbais estabelecidas entre a mediadora e os alfabetizandos com foco nas perguntas indagativas que perpassam as diferentes categorizações construídas no EJA. Para a análise dos excertos, trazemos o
Quadro 2, com a legenda dos recursos utilizados nas transcrições.

Quadro 2 - Legenda das transcrições

\begin{tabular}{|l|l|}
\hline \multicolumn{1}{|c|}{ LEGENDA } \\
\hline /letra/ & Representação fonética \\
\hline letras - letras & Separação silábica na fala \\
{$\left[\begin{array}{l}\text { [..] } \\
\text { Todos }\end{array}\right.$} & $\begin{array}{l}\text { Todos alungamento dos sons na fala } \\
\text { tempo. }\end{array}$ \\
\hline $\begin{array}{l}\text { Nome de mais de } \\
\text { um aluno }\end{array}$ & Falaram ao mesmo tempo mesmo \\
\hline [ ] & Descrição do comportamento. \\
\hline
\end{tabular}

Fonte: Elaborado pelas autoras

Quadro 3 - Excerto da escrita da palavra TEIA

\begin{tabular}{|c|c|c|}
\hline 01 & Mediadora & $\begin{array}{l}\text { TE-I-A, você fez o } T \text {, Geralda? Olha aqui, coloca aqui o papel no } \\
\text { meio para todo mundo ver. Observem, TEIA. [Mediadora } \\
\text { centraliza o papel para todos lerem] }\end{array}$ \\
\hline 02 & & [Registro: DIA] \\
\hline 03 & & [Todas as três tentam ler a escrita em voz baixa] \\
\hline 04 & Mediadora & TEIA. [mediadora pronuncia novamente a palavra em voz alta] \\
\hline 05 & Ivone $^{i}$ & Eu acho... O que que você acha? [Pergunta para a mediadora] \\
\hline 06 & Mediadora & $\begin{array}{l}\text { O que que vocês acham, gente? TEIA. [mediadora retoma a } \\
\text { pergunta para o grupo] }\end{array}$ \\
\hline 07 & Luzia & $\begin{array}{l}\text { TE-I-A, pra mim eu acho que tá certo, né? [Referindo-se à escrita } \\
\text { produzida: DIA] }\end{array}$ \\
\hline 08 & Geralda & $T E-I-A$. \\
\hline 09 & Mediadora & $\begin{array}{l}\text { Vocês acham que estão todas as letras aí? Lê pra mim aqui, olha, } \\
\text { que letra é essa? }\end{array}$ \\
\hline 10 & Geralda & $\hat{E} o T, I \ldots$ \\
\hline 11 & & $\begin{array}{l}\text { [Geralda soletra a letra T e a letra I quando tenta ler a escrita } \\
\text { DIA] }\end{array}$ \\
\hline 12 & Ivone & $T E-I-A$. \\
\hline 13 & Luzia & [Luzia conta nos dedos] \\
\hline 14 & Mediadora & $T E-I-A$. \\
\hline 15 & Ivone & $\begin{array}{l}\text { Eu acho que tem de trocar o A aqui. [Referindo-se à posição da } \\
\text { letra A na escrita DIA] }\end{array}$ \\
\hline 16 & Mediadora & Você acha que troca o A de lugar? \\
\hline 17 & Ivone & Ah, não, acaba com A mesmo, isso mesmo. Não precisa trocar. \\
\hline 18 & Mediadora & $T E-I-A$. \\
\hline 19 & Ivone & Acaba com A, não é? [Pergunta para a mediadora] \\
\hline 20 & Mediadora & Termina com A? TEIA? \\
\hline
\end{tabular}

Fonte: Elaborado pelas autoras 
Iniciamos a análise mostrando a categoria questão - em específico as subcategorias inferência /indagação e confronto -, na qual ocorreu o maior número de estratégias que possibilitaram aos estudantes a produção da escrita alfabética, através da inferência e da reflexão sobre suas próprias hipóteses. Sabemos que é a partir do ato de inquirir que podemos confirmar hipóteses e colocar conflitos para que o sujeito avance em suas concepções (ALVES MARTINS; SALVADOR; FERNÁNDEZ, 2017). Nas mediações que envolviam comportamento de inferir/ indagar, vimos que os sujeitos do EJA respondiam aos questionamentos da mediadora de forma reflexiva, mas com maior participação de alguns e maior escuta de outros, de acordo com seu perfil pessoal. Nesse momento, a mediadora exercia um papel questionador, ao mesmo tempo em que estimulava o confronto das hipóteses individuais ou coletivas.

Nota-se, pelo trecho ilustrativo, que a mediadora exerce um papel questionador e de confronto, com uma ação de devolver a pergunta ao participante para que ele a remeta aos colegas de grupo, na busca de promover maior interação e reflexão mútua. Outras perguntas em tom de indagação são anunciadas pela mediadora, como a presente na linha 9, "Vocês acham que estão todas as letras aí?”, que realiza um movimento de retorno à análise da escrita, buscando confirmar ou refutar a hipótese. Em outra pergunta, a mediadora questiona a aluna sobre uma mudança de posição da letra na escrita: "Você acha que troca o A de lugar?” (linha 16). Isso é descartado posteriormente pela própria aluna. Os exemplos demonstram vários questionamentos realizados pela mediadora, visando à exposição e à revisão de uma hipótese, sua defesa, reafirmação ou negação, dependendo do contexto em que a escrita estava se desenvolvendo. Nesses momentos, também evidenciamos seu papel de gestora na condução da interação entre os integrantes, como nas atitudes presentes nos exemplos das linhas 1 e 6 .

Com efeito, os estudos do PEI mostram que o discurso do mediador vai além da função instrutiva e reguladora, na medida em que se caracteriza por uma ação pedagógica diferenciada, que "adota estratégias promotoras da participação ativa e cooperação entre pares, estimulando um processo reflexivo de elaboração para a resolução coletiva da tarefa" (ALBUQUERQUE; ALVES MARTINS, 2019, p. 189).

Em outro momento da escrita, a mediadora usa como estratégia de mediação o recurso de ler a escrita já produzida no momento em que percebe uma paralisação ou esgotamento do grupo, para assim fazer emergir novamente a reflexão sobre a palavra. O objetivo é fornecer pistas para facilitar a correspondência letra-som. A mediadora pergunta qual letra falta para corresponder corretamente àquele som, já que o que está escrito ainda não corresponde à palavra desejada. Apresentamos, a seguir, o segundo trecho para exemplificar. 
Quadro 4 - Excerto da escrita da palavra MEDO

\begin{tabular}{|c|c|c|}
\hline 01 & & [Registro feito pelas alunas: $\mathrm{MTO}]$ \\
\hline 02 & Mediadora & $\begin{array}{l}\text { Olha aí... ME-DO. Que som é esse? [Aponta para a sílaba TO do } \\
\text { registro MTO] }\end{array}$ \\
\hline 03 & Geralda & $T$. \\
\hline 04 & Mediadora & T... T com O éTO. \\
\hline 05 & & [Geralda faz uma expressão de espanto e Luzia começa a rir] \\
\hline 06 & Mediadora & T com O é qual som? \\
\hline 07 & Luzia & Você quer escrever DO? \\
\hline 08 & Mediadora & DO. \\
\hline 09 & Geralda & $M E-D O, M E-D O$. \\
\hline 10 & Ivone & $M E-D O$. \\
\hline 11 & Luzia & $M E-D O, a h !, M E-D O$. \\
\hline 12 & Mediadora & ME-DO. Isso mesmo! \\
\hline 13 & Ivone & $M E-D O ?$ \\
\hline 14 & Mediadora & É. Isso. \\
\hline 15 & Ivone & É o O. Termina com $O$. \\
\hline 16 & Luzia & $\begin{array}{l}\text { Ah, "eu estou com MEDO". [Busca o sentido e uso da palavra } \\
\text { MEDO] }\end{array}$ \\
\hline 17 & Luzia & Tem o $D ?$ \\
\hline 18 & Mediadora & $\begin{array}{l}\text { O que vocês acham? [Mediadora lança a possibilidade para o } \\
\text { grupo] }\end{array}$ \\
\hline 19 & Mediadora & A Luzia acha que tem o D. O que vocês acham? \\
\hline
\end{tabular}

Fonte: Elaborado pelas autoras

No Quadro 4, vimos que a mediadora utiliza o recurso de ler o que eles escreveram em voz alta, além de ler pausadamente, alongando o som das sílabas, como um exercício de gerar pistas fono- lógicas. No exemplo da palavra MEDO, nas linhas 2, 4, 6 e 8, a mediadora focou na observação do som de uma sílaba para centralizar a atenção do grupo no som final da palavra. Nas cenas seguintes, 
as estudantes fazem a oralização da palavra proposta, e a mediadora reforça o comportamento seguindo a mesma atitude (linhas 9-15). Depois que a aluna Luzia apresenta a estratégia de dar sentido à palavra com seu uso em uma oração, a letra $\mathrm{D}$ é percebida e anunciada pela própria aluna (linhas 16 e 17). Segundo os estudos de Ferreiro (2011, p. 164),

[...] ir letra por letra na leitura não é uma boa estratégia para captar o sentido, mas ir letra por letra é obrigatório na escrita, já que não há maneira de produzir todas as letras ao mesmo tempo.

Nesse caminho, o movimento de centrar as atenções na descoberta da letra e, em seguida, ler a produção já realizada, para então relembrar a palavra proposta, foi uma estratégia eficaz com os alunos do EJA, em um movimento progressivo de foco no som e nas letras que compõem a palavra.

Vimos, assim, que a categoria pista foi um recurso facilitador para análise da palavra e reflexão fonológica dos estudantes adultos. Segundo Soares (2016, p. 185), “[...] a capacidade de divisão em sílabas da cadeia oral da fala - palavras ou frases - manifesta-se, ao contrário, de forma espontânea, desde muito cedo". Percebemos que, para os alfabetizandos adultos que estão em fase inicial de apropriação do sistema de escrita, assim como para as crianças, a divisão silábica, feita de forma oral, é um recurso importante e necessário para sua análise sobre as propriedades da língua.

No momento de levantamento de uma hipótese, como o anúncio de uma letra pelo participante (linhas 17, $18 \mathrm{e}$ 19), também percebemos que algumas mediações que podem ser vistas como a gestão do grupo ou como uma retomada para incentivar as análises entre os participantes. São momentos em que vivenciamos uma sequência de interfaces entre as categorias, cumprindo com o objetivo de mediação, que é auxiliar no processo de reflexões entre os sujeitos dos grupos.

Nesse mesmo percurso de análise, os trechos ilustrativos evidenciaram as categorias retomada e avaliação, que, assim como a categoria pista, são consideradas elementos mediadores importante para os grupos do EJA. ${ }^{6}$ Nos trechos da palavra MEDO, notamos a ação da mediadora de retomar a palavra trabalhada, como na frase presente na linha 12: "ME-DO. Isso mesmo". Em muitos momentos, a retomada, em conjunto com a pista e a avaliação, desencadeava uma volta ao raciocínio que os estudantes já tinham estabelecido, avançando em seu processo de análise.

De forma conjunta com esse comportamento, percebemos que também era necessário um movimento de apoio e estímulo "ao risco e à tentativa", por parte da mediadora, com os estudantes 
do EJA. Como já dissemos em outros momentos, na análise das sessões e nas categorizações, vimos a recorrência do posicionamento de incentivo da mediadora para promover maior participação e autonomia dos participantes. Muitos demonstravam receio em expor sua opinião, com timidez e reduzida exposição para anunciar suas hipóteses e ideias.

Sabemos, pelos estudos sobre os sujeitos jovens e adultos e pela própria prática docente com o EJA, que os estudantes em processo de alfabetização chegam à escola com muitas marcas de exclusão e histórias de vida marcadas pela posição de pouco domínio da cultura do escrito, e isso pode interferir no seu processo de aprendizagem (GALVÃO; PIERRO, 2007). Nesse sentido, acreditamos que a busca pela autonomia e pelo protagonismo tem de ser constantemente trabalhada com esse público. Frases do tipo "Nossa, eu não aprendo não.", “Tem de quebrar a cabeça.", "Estou muito ruim hoje.", "E se eu colocar e estiver errado?", "Com certeza deve estar errado." foram ditas durante as sessões e ilustram essa condição emocional. Além disso, a própria disposição do corpo nas sessões, com expressões faciais e uso das mãos demonstrando tensão e desconforto, evidenciam o esforço que os estudantes faziam para se exporem aos demais presentes.
Por causa dessas singularidades, também destacamos a categoria feedback como uma mediação singular no desenvolvimento das sessões com os sujeitos do EJA. Observamos a necessidade de a mediadora se posicionar com falas de apoio e reafirmação às ideias do estudante, motivando sua participação. Nesse caso, foram falas que traziam características das subcategorias incentivo e avaliação. Essas mensagens eram anunciadas com olhares e falas como: "Você acha que tem essa letra, então coloca para ver.", "Isso, escreve!", "Confia no que a sua colega falou.".

$\mathrm{Na}$ análise das categorias, vimos que a frequência da subcategoria incentivo foi diminuindo no avançar das sessões, demonstrando que a participação e a colaboração entre os integrantes do grupo ocorreu com maior frequência no decorrer das sessões. Ao final dos encontros, algumas falas demonstravam apreensão por vivenciarem a possibilidade de erro ou acerto na escrita das palavras quando a mediadora propunha a exposição da escrita hipotética (escrita convencional). Isso pode ser visto a seguir, no terceiro excerto. 
Quadro 5 - Excerto da escrita da palavra VIU

\begin{tabular}{|c|c|c|}
\hline 01 & Mediadora & $\begin{array}{l}\text { Vamos conferir então para ver se realmente está faltando uma letra, } \\
\text { ou se não está faltando letra. Vamos conferir, olhem [Apresenta a } \\
\text { escrita convencional]. }\end{array}$ \\
\hline & & [As alunas observam a escrita convencional]. \\
\hline 02 & Ivone & Ah, ela é pequena, olha! \\
\hline 03 & Ivone & Isto! \\
\hline 04 & Luzia & Está certo? \\
\hline 05 & Mediadora & Olhem aqui. As letras $V, I, U$. \\
\hline 06 & Luzia & $A h ! !$ \\
\hline 07 & Mediadora & São três letras, está faltando alguma? \\
\hline 08 & Luzia & Não. Pra mim não está. \\
\hline 09 & Mediadora & Mas é isso aí, mesmo. Muito bem! Vocês escreveram VIU. \\
\hline 10 & Geralda & Oh, gente! [Expressão de alívio] \\
\hline 11 & Mediadora & Só isso. \\
\hline 12 & Geralda & Graças a Deus, até que enfim nós conseguimos! \\
\hline
\end{tabular}

Fonte: Elaborado pelas autoras

Pelos exemplos acima, vimos que, ao final da escrita, muitos se portam com falas e expressões de alívio e felicidade, ou frustração e despontamento por não terem chegado à escrita convencional. Nesse momento, a mediadora continua assumindo a posição de incentivadora, demonstrando que a hipótese que eles tinham levantado sobre a escrita tem fundamento, como se vê na linha 9 . Também exerceu a função de síntese ao trazer as letras registradas pelas estu- dantes e a demonstração de que eram similares à escrita do registro convencional. Ressaltamos que as mediações e os modos de realizar a comunicação dialógica com os sujeitos de nossa pesquisa foram fundamentais para reforçarmos a importância do papel mediador na reflexão e na construção da escrita e suas implicações, dentro da perspectiva de desenvolvimento e aprendizagem de Vygotsky (1979). 
Em uma análise geral, as categorias gestão, questão, pista e feedback foram consideradas estratégias importantes para os grupos pesquisados da educação de jovens e adultos. Segundo os estudos de Morais (2012), os alfabetizandos podem se beneficiar desses tipos de intervenção à medida que são levados a refletir sobre as palavras em suas dimensões sonoras ao mesmo tempo em que analisam as formas gráficas e seu sentindo usual na língua falada e escrita. São algumas intervenções da mediadora ao longo das sessões que vão captando a atenção dos estudantes para os sons que compõem as palavras e para as letras que eles podem codificar, estabelecendo a análise oral e relacionando-a ao sistema escrito.

Com a análise das categorizações nos grupos do EJA, vimos que as ações da mediadora interferem no comportamento e nas ações dos sujeitos envolvidos, e cabe a ela o papel de organizar, conduzir e promover qualitativamente a participação dos integrantes durante a escrita das palavras, de modo a envolvê-los progressivamente na escrita colaborativa. Vimos que, além das perguntas que geraram reflexões metalinguísticas (na categoria questão, mais recorrente nas sessões), o feedback e a retomada também tiveram papel central com os grupos do EJA, com a presença de orientações para facilitar o funcionamento do grupo e gerar fluxo das discussões, além de ações de apoio à maior participação dos sujeitos, buscando a exposição de suas ideias e escuta da fala dos colegas. A estratégia de fornecer pistas fonológicas (categoria pista), com alongamento e oralização pausada dos fonemas, também contribuiu para que os alunos analisassem a sequência da palavra e se mostrou importante para o processo de análise e progressão da escrita com os grupos de alfabetização da EJA.

As categorias agrupadas neste estudo traçaram uma escolha para compreender as estratégias utilizadas na escrita inventada com o EJA, analisando seus efeitos para o perfil dos grupos selecionados. $O$ processo com sujeitos da alfabetização de jovens e adultos evidenciou a relevância de analisar qualitativamente determinadas mediações e nos mostrou a importância do respeito aos tempos e às singularidades do público da EJA, buscando compreender melhor como ocorre seu processo de aprendizagem e construção da escrita no campo da alfabetização com adultos.

\section{Considerações finais}

O principal objetivo deste artigo foi analisar as mediações agrupadas em categorias no desenvolvimento de um programa de intervenção de escrita inventada (PEI) com alfabetizandos da educação de jovens e adultos em fase inicial da leitura e escrita. A análise das mediações com o público do EJA revelou 
progressos nas atitudes e dinamismo dos alfabetizandos, apresentando avanços no processo de interação dos alunos entre si e em sua relação com a mediadora. Em uma análise qualitativa das mediações, relacionamos as características da mediação com avanços no processo de maior autonomia e participação entre os pares sujeitos da pesquisa. Os grupos de alfabetizandos do EJA demonstraram avançar gradativamente no seu processo de aprendizagem, com maior cooperação e escuta, refletindo em seus avanços individuais. O nível de desenvolvimento proximal, ou seja, aquilo que eles conseguiam realizar com a ajuda uns dos outros e da mediadora, demonstrou que a aprendizagem, quando organizada adequadamente, é capaz de despertar processos internos de desenvolvimento que dificilmente ocorreriam de outra forma (VYGOTSKY, 1989).

Segundo os estudos de interação com a escrita inventada, as características do programa têm certamente um papel decisivo nos resultados obtidos. Tanto a colaboração entre pares como a mediação da pesquisadora foram fundamentais para a dinâmica de interação que surgiu ao longo das sessões. Com efeito, a exposição a situações-problema (no caso, a escrita de palavras) que requerem discussão e resolução coletiva foi apoiada pela mediadora, que desempenhou o papel de facilitadora e promoveu a reflexão por parte dos alunos, ao mesmo tempo em que direcionou o discurso e incentivou a participação ativa de todos. Esses, segundo Pontecorvo et al. (2005), são processos essenciais para o desenvolvimento e a aprendizagem. Nesse sentido, foi importante fomentar a autonomia dos alunos dentro da dinâmica de construção coletiva do conhecimento e estimular a comunicação e partilha de diferentes pontos de vista (ALBUQUERQUE; ALVES MARTINS, 2018).

Com efeito, os resultados da análise das dinâmicas de interação em nossa pesquisa vão ao encontro das pesquisas com a escrita inventada que apontam o PEI como um programa impulsionador de mecanismos facilitadores no desenvolvimento e na aprendizagem, uma vez que promove a participação ativa na discussão e na reflexão sobre a língua, tendo o papel das mediações sociais uma função protagonista neste processo. (ALVES MARTINS; SALVADOR; FERNÁNDEZ, 2017).

Os resultados das pesquisas portuguesas e brasileiras mostraram que expor os sujeitos a situações nas quais eles precisam argumentar e se envolver na construção de uma solução coletiva para um problema na escrita favorece o desenvolvimento da compreensão da lógica do sistema de escrita alfabético. Também revelaram a eficácia do PEI para a construção da autonomia das crianças e dos jovens e adultos (ALBUQUERQUE; ALVES MARTINS, 2019; 
RESENDE; MONTUANI, 2019; OLIVEIRA; MACIEL, 2019). A categorização das mediações também nos fez refletir sobre a importância de os professores alfabetizadores da EJA possuírem um consistente repertório de mediações, ou seja, de terem conhecimento sobre suas próprias ações, que podem partir de uma pergunta bem formulada e fazer com que o sujeito pense e foque a sua atenção, além de promover um conflito cognitivo que aponte para o caminho da compreensão. (ALBUQUERQUE; ALVES MARTINS, 2019).

É evidente que os professores já possuem estratégias similares àquelas que foram vivenciadas nessa pesquisa quando promovem intervenções com seus estudantes com o objetivo de avançar no aprendizado do ler e escrever. Nesse sentido, os dados indicados são uma opção de reflexão sobre essas práticas, buscando estabelecer pontes entre o fazer docente e as pesquisas destinadas à compreensão do sistema de escrita alfabético.

Sendo assim, este estudo sugere a importância de incluir atividades de escrita inventada como prática pedagógica no contexto da alfabetização com adultos. Em uma análise qualitativa proposta nesse artigo, foi possível observar e acompanhar a evolução do processo de interação dos participantes entre si e com a mediadora a cada sessão, que demonstraram, ao final das sessões, estarem mais integrados e com maior protagonismo e participação. No caso da nossa pesquisa com adultos, se relacionar com o outro e se expor cada vez mais para ele foi considerado um grande avanço dos alfabetizandos da EJA em busca de autonomia e maior segurança para se posicionarem. Esses também foram considerados, por nós, elementos essenciais para sua aprendizagem na alfabetização.

Pedagogical mediation and the invented writing intervention
program in the youth and
adult literacy

\section{Abstract}

This investigation inserts itself in the theoretical framework of social interactionist studies and of collaborative research, and aims to analyze the strategies of pedagogical mediation in the written productions of young and adult groups of students in process of literacy. Analysis and categorization of mediations that took place during the invented writing intervention program (PEI) were carried out in dialogue with researches developed in Portugal and Brazil. Invented writing research is defined as an action that generates transformations in the thinking of the literacy student since it mobilizes his attention to the words' sound and to the shape with which they can be registered, favoring the process of metalinguistic reflection involved in the initial learning of written language. These interactions' set with the adult sub- 
jects demonstrated that the collaborative writing exercise can develop the process of individual and collective reflections towards the development of the apprehension of the written language.

Keywords: Pedagogical Mediations, Invented Writing Program; Literacy; Young and Adults Literacy.

\section{Notas}

1 A pesquisa seguiu todos os protocolos do COEP, segundo o processo n. 3.342.553, aprovado em 23 de maio de 2019.

2 As palavras utilizadas nos encontros foram compostas por sílabas com estrutura silábica (CVCV), (CVV) e (CVVV). São elas: VEIA VOVÓ - VIU - PELO - PATO - PAU - TEIA - TATU - TUDO - MEU - MAU - UMA - LUA - LUVA - LIA - DEDO - MEDO - MOLA - VELA - PULA - PATO. As constituições das palavras trabalhadas nas sessões foram monossilábicas e dissilábicas e, a maior parte delas, apresenta uma estrutura CVCV, por ser a mais simples na língua portuguesa. Os critérios utilizados levaram em consideração a extensão das palavras, a estrutura silábica e a relação de correspondência entre o nome da consoante inicial e sua escrita como sílaba inicial. Grande parte das palavras escolhidas fazem parte de outros estudos da Escrita Inventada do Grupo de Alfabetização (CEALE/FaE/UFMG), contudo, algumas modificações foram feitas com a substituição de palavras consideradas do universo infantil por palavras mais próximas ao vocabulário usual do público adulto.

3 Para conhecer com maior profundidade a estrutura do Programa de Escrita Inventada com adultos, ver o artigo das autoras (OLIVEIRA; MACIEL, 2019).

4 O Grupo de Pesquisa em Alfabetização (GPA) da Universidade Federal de Minas Gerais (UFMG) vem pesquisando e discutindo a importância de ter um quadro para macrorreferência de categorias de mediação no PEI. Este trabalho, de certa forma, utilizou categorias comuns às pesquisas que o antecederam.

5 É preciso deixar claro que as propostas para a escrita de todas as palavras foram inicialmente contextualizadas com os participantes.
$6 \quad$ Retomada e pista foram duas categorias com maiores pontos de contato em nossas análises. Por isso, necessitamos de um exercício contextual cuidadoso para percebermos as intenções da mediadora quando produzia falas para gerar lembranças ou para focar na análise da escrita da palavra.

\section{Referências}

ALBUQUERQUE, A.; ALVES MARTINS, M. Dinâmicas interativas em programas de escrita inventada: um estudo qualitativo em contexto de jardim-de-infância, Edições ISPA: Lisboa, p.169-186, abr. 2019.

ALBUQUERQUE, A., ALVES MARTINS, M.. Escrita inventada no jardim-de-infância: contributos para a aprendizagem da leitura e escrita. Análise Psicológica, Lisboa, v. 36, n. 3, p. 341-354, 2018.

ALVES MARTINS, M.; SALVADOR, L.; ALBUQUERQUE, A.; FERNÁNDEZ, M. "Otro niño lo escribió así". Ayuda educativa y resultados de actividades de escritura inventada. Revista de Educación, n. 377, p. 161-186, jul./sept. 2017.

ALVES MARTINS, M.; SILVA, C. O nome das letras e a fonetização da escrita. Análise Psicológica, Lisboa, v. 17, n. 1, p. 49-63, 2009.

FERREIRO, E. $O$ ingresso na escrita e nas culturas do escrito: seleção de textos de pesquisa. Trad. Rosana Malerba. São Paulo: Cortez, 2013.

FERREIRO, E.; TEBEROSKY, A. A psicogênese da língua escrita. Porto Alegre: Artmed, 1985.

FREITAS, M. L.; RIBEIRO, N. A.; MOURA, T. M. Alfabetização de jovens e adultos: ainda uma questão polêmica. In: SILVA, M. C.; CABRAL, A. C. (Orgs.). Práticas de alfabeti-

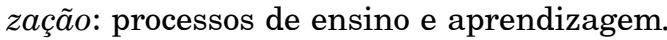
Recife: Edição UFPE, 2020. p. 195-208.

GALVÃO, A. M.; DI PIERRO, M. C. Preconceito contra o analfabeto. São Paulo: Cortez, 2007. 
KLEIMAN, A.; VÓVIO, C. L. Letramento e Alfabetização de pessoas jovens e adultas: um balanço da produção científica. Caderno Cedes, Campinas, v. 33, n. 90, p. 177-196, maio/ago. 2013.

LANZA, P. M. M. A mediação pedagógica na escrita espontânea com crianças de cinco anos. 2018. Dissertação (Mestrado em Educação) - Faculdade de Educação, Universidade Federal de Minas Gerais, Belo Horizonte, 2018.

MONTEIRO, S. M.; SOARES, M. Processos cognitivos na leitura inicial: relação entre estratégias de reconhecimento de palavras e alfabetização. Educação e Pesquisa, São Paulo, v. 40, n. 2, p. 449-466, 2014.

MORAIS, A. G. Sistema de escrita alfabética: como eu ensino. São Paulo: Melhoramentos, 2012.

OLIVEIRA, J. G.; MACIEL, F. I. O Programa de Escrita Inventada na Alfabetização de Jovens e Adultos: uma análise sobre a escrita de palavras. Revista Brasileira de Alfabetização - ABAlf, Belo Horizonte, v. 1, n. 11, p. 55-78, jul./dez, 2019.

RESENDE, V. B.; MONTUANI. D. F. A mediação pedagógica na Escrita Inventada de crianças no processo de alfabetização: palavras com estrutura silábica CVC e CV nasal. Educação em Revista, Belo Horizonte, v. 36, p. 1-36, jan./jul., 2020.

SOARES, M. Alfabetização: a questão dos métodos. Belo Horizonte: Contexto, 2016.

SPINILLO, A. G.; LAUTERT, S. Pesquisa-intervenção em psicologia do desenvolvimento cognitivo: princípios metodológicos, contribuição teórica e aplicada. In: CASTRO, L. R.; BESSET, V. L. (Orgs.). Pesquisa-intervenção na infância e juventude. Rio de Janeiro: NAU, 2009. p. 294-321.

VYGOTSKY, L. S. A Formação Social da Mente. São Paulo: Martins Fontes, 1989.

VYGOTSKY, L. S. Pensamento e Linguagem. Lisboa: Antídoto, 1979. 